\title{
Mujeres artistas del entorno Fluxus Pioneras del arte de acción
}

\author{
Women artists of the Fluxus environment \\ Pionners of performance art \\ Pilar Aumente Rivas \\ Profesora Emérita. Departamento de Comunicación Audiovisual y Publicidad II \\ Universidad Complutense de Madrid \\ pilaraumente@ccinf.ucm.es
}

Sumario: 1.- Introducción. 2.- Yoko Ono. 3.- Shigeko Kubota. 4.- Alison Knowles. 5.Kate Millet. 6.- Mieko Shiomi. 7.- Takako Saito. 8.- Bici Forbes (Hendricks). 9.- Annie Vautier. 10.- Daniela Palazzoli. 11.- Mary Bauermeister. 12.- Alice Hutchins. 13.- Anne Tardos. 14.- Carla Liss. 15.- Carolee Schneemann. 16.- Bibliografía.

\section{Introducción.}

En la abierta y fluida agrupación que surgió con carácter internacional en los comienzos de los años 60, conocida bajo la denominación de Fluxus, la participación de mujeres artistas fue numerosa y de gran importancia ${ }^{1}$.

Se puede afirmar que es la primera vez en la historia en la que la presencia activa de mujeres es tan amplia teniendo además en cuenta la envergadura de sus propuestas. Sus trabajos intermedia no fueron únicamente paralelos a los de otros

\footnotetext{
${ }^{1}$ La temprana fecha de presentación de este estudio, en el marco de las investigaciones españolas sobre la actividad de las artistas del entorno Fluxus, ha aconsejado la recuperación íntegra de esta ponencia en su versión original, sin modificaciones, tal como fue presentada en las I Jornadas Abiertas “Mujeres en el ámbito de la creación y la comunicación artística contemporánea". Universidad Complutense de Madrid, 25 y 26 de abril de 2001.
} 
miembros del grupo liderado por el artista lituano George Maciunas, sino que en muchos casos supusieron las bases para el desarrollo posterior del Performance Art tal y como lo entendemos hoy, y desde luego fueron las primicias, en algunos de ellos, de lo que conocemos hoy como arte protofeminista.

La voluntaria falta de precisión en los límites del movimiento, permitió una constante movilidad en los artistas que lo integraron, por lo que la nómina de mujeres vinculadas varía mucho a lo largo del periodo matriz. La bibliografía sobre el mismo no refleja de manera sistemática las aportaciones de las artistas que colaboraron, lo que provoca una imagen distorsionada de la fuerza de su presencia. Con frecuencia la referencia se ve exclusivamente plegada a los trabajos realizados por Yoko Ono , Shigeko Kubota, Mieko Sjiomi, y Alison Knowles, cuya aportación tuvo sin duda gran peso, pero olvidan valorar la actividad individual de Charlotte Moorman, o la vinculación en los primeros tiempos de andadura del grupo, de Carolee Schneemann y Kate Millet; asimismo ignoran participaciones más o menos constantes como las de Takako Saito, Bici Forbes (Hendricks), Alice Hutchins, Jane Knizak, Carla Liss, Annie Vautier, Mary Bauermeister, Anne Tardos, y otras cuya colaboración ha sido más ocasional.

\section{Yoko Ono.}

La obra que ha alcanzado mayor eco internacional ha sido, sin duda, la de la japonesa Yoko Ono, pionera en muchos aspectos y con capacidad innata para la difusión de sus aportaciones. Su papel en el entorno de Fluxus comienza en los propios inicios del mismo, en la configuración y desarrollo de un grupo cuyas actividades comienzan en el ámbito de la música pero con horizontes multidisciplinares. Los Chambers Concerts, también denominados Chambers Music Series, que son considerados hoy como el catalizador inicial mas importante en la aglutinación de Fluxus, fueron organizados por Yoko Ono junto con La Monte Young en el ático-apartamento de ésta en Chambers Street, Nueva York. Se desarrollaron en doce fines de semana a lo largo del periodo que va de 1959 a 1961. Estos eventos se convirtieron en un magnífico foro de intercambios entre los artistas más vanguardistas del momento. Alma de estas reuniones era la anfitriona, una joven japonesa de gran preparación, que con gran valentía se había enfrentado a su sociedad de origen y se movía con libertad en el panorama neoyorquino. 
Se había educado en una escuela para niños que compartían la experiencia de haber estado en el extranjero, más tarde se formó en una escuela cristiana exclusiva para miembros y familiares de la familia imperial y del parlamento japonés. Con posterioridad será admitida en la Facultad de Filosofía. Durante sus estudios universitarios Yoko fue contagiada por la ola de intelectualidad radical que se forjó tras la finalización de la segunda guerra mundial. Se vio influida por el marxismo y el existencialismo. Participó de los aires de libertad que alentaron el nuevo Japón. Gran número de publicaciones periódicas que impulsaron el cambio denunciaban el militarismo y el centralismo burocrático que el sistema imperial había impuesto. El pacifismo tomó fuerza y la impregnó. Como intelectual leyó a Hegel, Marx, Heidegger, Kierkegaard, Sartre, Malraux, Guide y conoció bien a los literatos rusos Dostoievski, Tolstoi, Chejov, Gorki, etc.

Esta preparación liberal le hace alejarse cada vez más de la cultura tradicional japonesa, de su propia sociedad y de su familia. Al trasladarse en 1952 a Nueva York se vinculó al Sara Lawrence College para mujeres liberales, en donde estaría dedicada a la poseía y la composición.

El mundo norteamericano estaba preparado para abrirse a sus raíces culturales. La presencia de filósofos orientales como Okakur Kakuzo, Ananda Coomaraswamy y D.T. Suzuki (que en 1950 pronunció una serie de conferencias en la Universidad de Columbia sobre el Zen) favorecieron el clima que acogió el talante y la obra de Ono.

Muchos de los participantes en los Chambers Series tenían un gran conocimiento de la música culta occidental. La propia Yoko había estudiado música y conocía bien no solo a los grandes compositores japoneses, sino que había aprendido piano en su niñez (su primer concierto lo realizó a los cuatro años). Poseía una fuerte vocación compositora que había debido reprimir en una sociedad como la japonesa en los años 40. Así mismo había aprendido canto y su voz estaba educada para cantar lieders alemanes. Entra en contacto con la música de vanguardia a través de su conocimiento de la obra de Schönberg y Von Webern. Su interés por la música de vanguardia será compartido por Toshi Ichiyanagi con quien terminará emparejándose. Ichiyanagi mantenía una buena relación con J. Cage quien le invitará a sus cursos en la New School 
for Social Research en el Greenwich Village de Nueva York donde Cage desarrolló su actividad desde 1958 (Zaya, 1989: 69)².

Instalada en su apartamento intensificará las relaciones con los artistas más activos y este quedará convertido en sede de experiencias artísticas en las que la experimentación y la búsqueda de nuevos caminos para el arte serán la constante. En el ámbito de los Chambees Series, presenta la performance Voice Piece, para soprano, en el Evening of Contemporary Japanese Music del Village Gate de Nueva York.

Quizá una de sus propuestas más rigurosas de entre las que presentó en Chambers y después en la Galería A.G. de Maciunas, es la que recogía obras que precisaban del pensamiento o de la acción de otra persona que las ejecutara o materializara, para existir. Se agrupaban bajo el título Instructions painting (1961). En ellas Yoko partía de la idea de separación entre concepción (lo que se correspondería con lo que ella denominaba instrucción) y la realización (o materialización) de la obra artística. Un ejemplo de esta forma de entender el arte puede apreciarse en las instrucciones para $A+B$ Painting:

Que alguien, que no seas tú, corte parte de la lona A. Pega la zona cortada en el mismo punto del B. Alinea la lona $A$ y la B y cuélgalas adyacentes una a la otra. Puede usar lonas blancas ofotografias ${ }^{3}$.

En otros casos deja que sea un agente externo no humano quien intervenga. Aunque al tratarse de algo previsible no deberíamos hablar de azar, ella lo considera un hecho azaroso. Así ocurre en Painting to let the evening light go through (1961). La obra es diáfana, para que, colgada ante una ventana, deje pasar la luz de la tarde. Las instrucciones indicaban:

Pon una botella detrás de una lona, pon la lona donde dé la luz del oeste. La pintura existirá cuando la botella produzca una sombra en la lona o, si no, no existirá. La botella puede contener licor, agua, hormigas o insectos que canten o no tendrá que contener nada. (Pintura para dejar que entre la luz de la mañana)4.

En las performances presentadas en el Carnegie Recital Hall de New York City, en noviembre de 1961 reclamó la atención del público. Entre los que co-

2 Para la gestación de Fluxus véase (Sichel, 2002: 87, 101 y 314).

${ }^{3}$ Esta es una pieza que por sus características se relaciona con la obra de Torn.

${ }^{4}$ Esta obra está en relación con Schadow painting. 
laboraban en la obra figuran artistas del entorno, como Yvonne Rainer, La Monte Young y Jackson Mac Low, George Brecht, Ay-o, Philip Corner, etc...

La invitación al público para que intervenga en la acción, supone el cambio de planteamiento respecto a la pasividad del espectador en la obra tradicional. Ahora bien, existe un matiz de diferencia en lo que se refiere a la solicitud de intervención en relación a lo que otros artistas estaban experimentando desde el enfoque del happening. En el caso de las obras de Ono, el espectador dejaba de serlo e intervenía uno a uno, y no en grupo. Yoko exigía un bis a bis con la obra. Eso es lo que requiere en trabajos como Smoke Painting en la que se instaba a la persona correspondiente a integrarse en el trabajo de Yoko y quemar un lienzo con un cigarro, tantas veces como quisiera, y contemplar el humo que se produce. Así sucesivamente hasta que el último espectadorperformer quemara el último trozo de lienzo y este desapareciera completamente. Sólo entonces acababa la acción. Este tratamiento está en relación con la inclusión de Ono en la corriente desmitificadora del artista como ser de capacidades excepcionales, de tal manera que se entiende que cualquier persona puede serlo si se tiene una actitud creativa y se deja a la imaginación correr libre ante una determinada situación. Yoko ya por entonces llamaba a estos trabajos CON-ART o conceptual-art. Alexandra Monroe ha reivindicado que estos son anteriores a la presentación en 1965 de One and tree chairs de J. Kosuth, considerado como el centro de las investigaciones conceptuales.

En esta misma línea pueden entenderse bastantes de las obras realizadas en los primeros años de la década del sesenta.

Durante su viaje a Japón en 1962, Ono continúa abundando en esta forma de vincular al espectador en una acción que en muchos casos no concluye en la materialización del objeto, sino que se consume en la propia acción llevada a cabo entre el artista y el espectador, que ha dejado de ser un mero contemplador y se ha convertido en un agente eficiente de la obra.

Cut Piece continúa en la misma línea conceptual, de solicitud del espectador para que lleve adelante la acción que la artista le propone, pero de una manera individual. Aunque se solicita la intervención de varias personas, se indica que lo hagan uno a uno. En la performance se presentaba Ono vestida con su mejor conjunto en el suelo del escenario sentada sobre sus piernas dobladas. Allí en solitario, se ofrecía a los espectadores, quienes, uno a uno, 
subían al escenario y cortaban con unas tijeras un trozo de su vestido, hasta que totalmente destrozado desaparecía. La interpretación sobre la intencionalidad de la pieza y el entorno que sugiere ha sido muy polémica y ha variado según el momento. En la versión de 1964 ha sido entendida (Tanner, 1994) como un trasunto de la vida de Buda, cuando permitió al tigre devorar su cuerpo. Ono, siendo la víctima, es vulnerable a la agresión no sólo de su aspecto personal, sino a la sexual, al voyeurismo y a la violencia de género.

También se han ofrecido lecturas de Cut Piece que apuestan por la significación de carácter pacifista, frente a la protofeminista que hoy es más aceptada. La propia Yoko ha ofrecido diversas interpretaciones y no ha especificado exactamente. Sin embargo, sí ha insistido siempre en la tensión que padece en esta pieza, e igualmente ha enfatizado la importancia que para ella tenía esta performance, lo que la llevaba a realizarla como ya hemos señalado, con sus mejores vestiduras, lo que abunda en el carácter ceremonial de la pieza.

Intérprete musical, compositora, cantante, performer, creadora plástica, creadora de films, colaboró asimismo en obras concebidas por otros, como en el caso de Shout (fluxfilm n⿳丷. 22, 1966), concebida por Jeff Perkins (según se le atribuye habitualmente), en la que este se enfrenta a gritos con su entonces marido, Anthony Cox. La contradicción y la antinomia son esenciales aquí, un film mudo en el que se revalorizan el gesto y la movilidad de lo plástico refiriéndose al grito que alude a lo sonoro, basando el trabajo en el cambio de estado psicológico y la expresión, aspectos que más tarde también se redefinen en el Body Art.

El interés de Ono por la paradoja le llevó a realizar fotogramas fijos en cine y a cámara lenta trastocando las características esenciales del cinematógrafo como captador y reproductor de movimiento. Igualmente pretendía alterar la forma de aparición en la imagen como en el caso de la versión reducida para ser proyectada en un cubo de un metro cubico durante la Fluxfest de John y Yoko en 1970.

Otra experiencia con el lenguaje cinematográfico, de la que todos sus films participaron en la línea de lo que Fluxus supuso, fue el Fluxfilm número 9. Eyeblink. Toma de un único movimiento de una seleccionada parte del cuerpo humano: el ojo derecho de Yoko parpadeando y recogido a cámara lenta. 
Pero el experimento minimalista en el que se ha querido ver un enlace con investigaciones anteriores como las de $\mathrm{H}$. Edgerton y J. Painlevé, fue su film Número1 (One) (Fluxfilm n⿳ำ 14) en el que se presenta a cámara lenta la filmación del acto de encender una cerilla y se recoge hasta el momento en que la cerilla se apaga.

Igualmente colaboró en otras formas de expresión artística y preparó obras o presentaciones conjuntas de otros artistas, un ejemplo de este aspecto lo tenemos en Look-Alike-Boxes of different weights, basado en una idea de Takako Saito. Un suelo inundado de agua con doce cajas de diferentes pesos que progresaban de lo ligero a lo pesado pegadas en él. Aunque este evento no se llevó a cabo en la práctica, estaba previsto en el programa de la Fluxfest presentación de John Lennon y Yoko Ono en abril de 1970. Estaba basado en el ajedrez en el que las piezas parecen iguales pero tienen diferentes pesos en su interior en correspondencia con el valor de cada pieza. El engaño como recurso lúdico-expresivo fue usado por Maciunas para su Raqueta muy pesada.

Durante ese periodo que se corresponde con su vinculación sentimental, John Lennon interviene en los trabajos, lo que nos muestra su capacidad para integrarse en acciones y realizaciones conjuntas. En la mayor parte de estas colaboraciones existe una gran armonía. Sin embargo, se ha hecho notar como Maciunas en cuya Galería AG expuso Yoko en los comienzos de los 60, marca una disensión o contradicción entre la propuesta de la artista japonesa y la parte que a Maciunas le tocaba desarrollar.

Vtre $n^{0} 7$ Fluxus 3 Newspaper febrero de 1966 está monograficamente dedicado a la obra de tres artistas: Yoko Ono, Ben Vautier y Jim Riddle. Maciunas ilustra gráficamente los trabajos presentados. En el caso de la obra de Ono se ha visto un contraste entre la poética del texto de Yoko y la extrañeza y brusquedad de las imágenes xilográficas introducidas por Maciunas, llegando a considerarse estas como perversas y con una "maligna ambivalencia" (L'Esprit de Fluxus, 1994: 206).

Una cierta prevención contra los trabajos de Yoko, -asunto que la propia Ono ha denunciado-, considerados por Maciunas y algunos otros de los miembros del entorno Fluxus "muy carnales", parece detectarse ciertamente, pero hay que afirmar no obstante, que al tiempo se observa cómo Maciunas, a pesar de todo, le facilitó la exposición en su galería AG y asimismo sus pelícu- 
las fueron incluidas de manera regular en las Fluxkit, al igual que lo eran las de Paul Sharits, Stan Vanderbeek y el propio Maciunas.

En efecto Maciunas le ofrece la posibilidad de exponer en la A. G. Gallery en la exposición que se inauguró el 16 de julio de 1961. Maciunas que fotografió la exposición gracias a lo cual podemos conocer lo allí presentado por Ono, consultó con la artista durante el período que duró la exposición la creación de un nuevo movimiento internacional y aunque ella no tuvo demasiado interés en el trabajo colectivo parece que influyó con sus posicionamientos artísticos, colabora a la concreción de lo que Fluxus sería a futuro en el sentido en que Maciunas lo desarrolla, a partir del momento en que finalmente decide darle el nombre por el que hoy es conocido y que presentará el importante desarrollo en el período entre 1962-64, etapa por otro lado en la que Ono estaba con John, motivo por el cual se ha afirmado que pudo existir un posterior abandono del interés de Maciunas por la obra de Yoko. Sin embargo, hay que recordar que seguirá siendo incluida constantemente en las actividades colectivas del grupo y se conservó buena relación entre ellos, incluso en época más tardía tras su vinculación a Lennon. Para la exposición del Everson $\mathrm{Mu}$ seum, Ono llamó a Maciunas para que le ayudara en la producción de obra y en la edición, aunque este hecho se organizaba fuera del entorno Fluxus. Maciunas continuó incluyendo a Ono hasta el final de sus días, (1978).

Participó como intérprete en Disappering Music for face (1966). Se trata de la versión filmada de una idea que originalmente puso en marcha Mieko (Chieko) Shiomi en versión de performance realizada por ella misma en 1964. Se trataba de poner ante el espectador el proceso de desaparición de una sonrisa. El evento fue conocido por Maciunas. Más tarde cuando se presentó la posibilidad de utilizar para filmar con ella, una cámara profesional con un obturador que captaba 2.000 imágenes por segundo, se les ocurrió utilizarla para filmar experiencias FLUXUS, en la línea de lo que Maciunas denominó "ideas rápidas". Según ha contado la propia Yoko Ono, a ella le venía rondando la idea, desde hacía tiempo de filmar algún acto natural y especialmente una sonrisa.

Maciunas no accedió en un principio a que ella lo rodara, porque como luego después explicó, le parecía que la idea pertenecía a Mieko, que ya la había utilizado en su performance de 1964. Más tarde Yoko afirmaría que sólo 
pasado un tiempo se había dado cuenta de que eran dos ideas diferentes. A ella le atraía la idea de filmar una sonrisa, a Mieko lo que le interesaba transmitir era la desaparición de la sonrisa. Finalmente Maciunas accedió a que Yoko interpretara la obra de Shiomi manteniendo su autoría.

Ese deseo de filmar un hecho antiespectacular subrayando la importancia de lo cotidiano, anima a Ono a realizar Eye Blink (Fluxfilm no9), (1966) que sigue el mismo esquema de plano secuencia. De nuevo se trata en este caso de un proceso, el paso de un ojo cerrado a su situación de ojo plenamente abierto. Esta toma de un hecho fugitivo queda paradójicamente perpetuada a través de la utilización de la cámara rápida utilizada por el mismo fotógrafo filmador: Peter Moore.

Se ha señalado cómo Yoko Ono establece una relación especular entre el espectador y la pantalla. El ojo sobre la pantalla ha sido filmado por el ojo de la cámara y se muestra al ojo del espectador, el cual ve su actividad visual confrontada a su propia imagen (Aubert, 1998: 11). Hace consciente al espectador de su condición y la experiencia de una contemplación activa enfrentada al gesto filmado se convierte a la vez en sujeto y objeto de la obra. Así la atención que se da a las pequeñas cosas de la vida, a aquellas que no parecen tener consecuencias, puede ayudar a comprender mejor el mundo.

En ese espíritu hay que interpretar One de 1966, un film realizado con las mismas condiciones técnicas en el que se aprecia el proceso de duración de la llama producida por una cerilla desde que es encendida hasta que desaparece. Es al igual que los anteriores films mencionados, una obra muda, pero en este caso, los efectos visuales de la llama al ser vistos a cámara lenta (en realidad cámara de filmación rápida) añaden un factor de atracción desde el punto de vista estrictamente perceptual. El agotarse en el esplendor del uso es aquí ejemplificado de manera atrayente. La belleza de la inmaterialidad de la llama nos hace culminar en pensamientos de mayor profundidad al ser visto de manera que la mirada cotidiana no nos permite ver. Se trata de hechos aparentemente intrascendentes, pero, desde luego inusuales como sujetos de un film.

A pesar de que se ha discutido en alguna ocasión el protofeminismo a ciertas obras de Ono como Cut Piece, remitiéndolo a criterios exclusivos de pacifismo y antiviolencia, denuncia de racismo etc., y teniendo en cuenta que se ha recordado con frecuencia que la propia Ono respondió en 1994 durante una 
entrevista realizada por Robert Enright, que ella no había tenido ninguna opción de feminismo en esa actividad, lo cierto es que no se reducen a esta obra las reflexiones de Ono sobre el mundo de la mujer en su etapa temprana. City Piece, de 1961, hace referencia al acto de pasear por la ciudad con un cochecito de niño vacío, volviendo a redefinir una acción tan cotidiana en la mujer.

Uno de sus films, el no 8, titulado Woman (1968), se centra en el embarazo y el parto, e igualmente una buena parte de las partituras de las performances recogidas en Grapefuit, (compilación de 1964), son estudios sobre la naturaleza fisiológica y aspectos psicológicos de la intimidad. Enfoques que centraron en su momento y siguen siendo puntos de revisión de la teoría feminista: la toma de contacto con el cuerpo, con ciertas zonas, órganos y sistemas que integran nuestro cuerpo. Se ha apuntado que partituras como Pulse Peine 1963 o Beta Peine, del mismo año, así Body Sound Tape Piece de 1964 que exploran la atención al corazón y al sistema circulatorio, o bien tratan de la atención al sonido interno, el equivalente sonoro de ciertas emociones, hacen referencia a sensaciones intimas o a sensorialidades poco exploradas que se han valorado como anticipación de "temas del feminismo esencialista" que se desarrolló en los años 70 y que se ha considerado prefiguración del feminismo de Luce Irigaray con cuya teoría se abandona la primacía del tacto basada en propias características derivadas de las zonas sexualizadas de la mujer.

De 1964 es el film de Yoko nº 4, Four, fluxfilm nำ16. Con el título se hace referencia no sólo al código de clasificación, sino al contenido de la película. El encuadre de los planos secuencia acoge cuatro series de cuatro nalgas. De ahí, parece ser, proviene su título. Aunque se pensó en filmar 365 nalgas, tantas como días tiene el año, finalmente quedó en la serie que tiene como número referencial el cuatro. En ella se muestra una serie de primeros planos de nalgas en movimiento (las de Susane Campbell, Philip Corner, Bici y Geoffrey Hendricks, Benjamin Patterson, Jeff Perkins, Susan Poland, Carolee Schneemann, James Tenney, Pieter Vanderbeek, Verne Williams, la propia Yoko Ono, el que fue su marido Anthony Cox y, se ha llegado a decir, de la hija de ambos Kyoko (Aubert, 1998: 14) aunque habría que recordar que esta nació en 1963. De la obra se rodaron dos versiones. La primera, en la que intervinieron los arriba mencionados, se filmó en el apartamento de Yoko en Nueva York. Una versión posterior, más larga, se rodó en Londres en el apartamento de su amigo Victor Musgrave. Con independencia del aspecto plástico de las zonas 
anatómicas en movimiento y el sentido tanto de atención al cuerpo como de ruptura de tabúes, de carácter igualatorio de lo natural frente a las convenciones de diferenciación social al uso, el film supone una fórmula de presentación de cuerpos desnudos que no presentan las zonas de diferenciación sexual que suelen aparecer habitualmente en las obras de arte; la relación desnudo masculino-femenino se diluye. Lo plástico se alía con lo político de forma muy radical e irreverente en su momento. El film es vulgarmente conocido como Bottons.

Con posterioridad Yoko realizó Rape en la que se presenta el acoso y la persecución, así como la pérdida de la intimidad como elementos de reflexión. La cámara persigue sin tregua a una joven en un cementerio hasta llegar al agobio extremo.

Por su parte la película Fly, realizada ya en 1970, presenta el cuerpo de una mujer, primero recorrida insistentemente por una mosca, y finalmente por varias. La misma Yoko presta su voz a la mosca que produce sonidos parecidos a los zumbidos característicos del insecto. La mosca que se posa en los senos y sexo de la mujer establece ese oscilar de la atención del espectador. Ono se cuestionaba sobre cuál de los dos elementos, el cuerpo de la mujer y sus zonas erógenas, o la mosca captará la atención del espectador. La obra se lee como crítica y protesta hacia el maltrato y la degradación sufrida por las mujeres. Touche Piece (1969) se ha visto como un ejemplo claro en esta línea ${ }^{5}$. Las interpretaciones que se centran en características no vinculadas al interés feminista no contradicen ni se oponen a la interpretación de vinculación con el zen, en lo relativo a la concentración, indagación y reflexión sobre el cuerpo que la filosofía oriental contempla.

En esta dirección de relación con el feminismo habría que entender la invitación por parte de la Organización Nacional de la Mujer para su International Women's Conference en junio de 1973, en Cambridge, Massachusetts. Ella preparó un bloque de canciones elaboradas especialmente para ello. En alguna ocasión ha recordado como cantó en conjunto con todas las mujeres presentes formando un potente coro.

\footnotetext{
${ }^{5}$ Kevin Concannon. Yoko Ono's Cut Piece: Critical Reception. 1997. Third Annual Performance Studies Conference. Atlanta, 11 abril 1997.
} 
Ya en 1971 había escrito un texto, publicado en 1972 en el New York Times en forma abreviada, y completa en el Sundance Magazine en el mismo año, en el que habla de la feminización de la sociedad. En él no sólo se defiende el derecho de la mujer a la integración en la vida activa de la ciudad, a través de la incorporación cada vez más amplia de la mujer al mundo del trabajo, sino que se señala, cómo uno de los principales objetivos y signo del cambio de los tiempos (década de los 70), era precisamente la atención al lesbianismo y su reconocimiento como una forma de rebelión hacia la sociedad existente.

También señala cómo una vez reconocida la libertad de la mujer para desarrollar su sexualidad, se deben encontrar aspectos adecuados para la coexistencia con los hombres haciéndolo armónicamente para conseguir una sociedad plena. La solución pasa por una mayor participación de los hombres en las tareas que históricamente la han sido encomendadas a las mujeres, y para Yoko Ono, existía una tarea de importancia superior que podía ser la clave para el cambio hacia esa meta: que el hombre compartiera la tarea del cuidado de los niños, lo cual exigía un cambio de pensamiento en los hombres de esa generación. Las mujeres lo habían pedido. Históricamente se les había impuesto un lugar y unas tareas y eso no había llevado al mejor de los mundos. Si actuando así el hombre no había conseguido un mundo satisfactorio, era debido a que ese mundo estaba basado en la opresión, la codicia y frustración. Feminizando la sociedad, dando lugar a que la mujer encuentre libremente su lugar, se alcanzará un mundo mejor ${ }^{6}$.

Conversation Piece (1962) de Ono, entra de lleno en las tendencias de las mujeres artistas para crear conciencia sobre el dolor, la indefensión y el desamparo. En una línea de fisicalidad que algunos críticos le han valorado negativamente, Yoko asociaba el vendaje de alguna de las partes del cuerpo de la mujer al dolor. Unido al sentido de las palabras, el mero acto de hablar se erige en performance global de la herida y del dolor psicológico. El texto dice así ${ }^{7}$ :

Venda cualquier parte del cuerpo.

Si la gente te pregunta, inventa una historia

\footnotetext{
${ }^{6}$ Además de estar incluida en otras publicaciones, véase: Munroe, 2000; Hendricks et al. Yes Yoko Ono. New York, Japan Society; Abrams 2000; una versión de este texto puede ser fácilmente consultada a través de la página web de la Fundación Yoko Ono.

${ }^{7}$ Ono, Y. Grapefruit 2a ed. New York, Simon and Chuster, 1970, en L“Esprit de Fluxus, 1994: 218.
} 
y cuéntasela.

Si la gente lo olvida, recuérdaselo

Y sigue contándosela.

No hables de nada más.

Se ha querido ver en ello un adelanto de las teorías feministas que reflexionan sobre el rol del habla y la escucha en la construcción del conocimiento femenino.

\section{Shigeko Kubota.}

La japonesa Shigeko Kubota es una de las artistas más activas que formaron parte de Fluxus. Cercana y valorada por Maciunas, fue introducida en el círculo Fluxus por Yoko Ono, quien le presentó al lituano. Ella venía de desarrollar una interesante labor en el entorno del grupo Ongaku en Japón, con el que había entrado en contacto gracias a la influencia de una tía suya que era bailarina y que había incorporado a alguno de los componentes del grupo en sus espectáculos. Ongaku, que se había formado en 1961, fue un grupo que despertó interés por su continuo deseo de innovación y por la utilización simultánea de distintos medios expresivos. A lo largo de su trayectoria los componentes del grupo estimaron la labor de Marcel Duchamp, lo que coincide con el histórico entusiasmo de Kubota por el francés. En el año 1962 J. Cage, que con anterioridad ya había sido influido por el pensamiento Zen, y D. Tudor visitaron Japón. Shigeko asistió a alguno de sus conciertos y llegó a la conclusión de que si la música de Cage era aceptada en Nueva York, la suya también habría de serlo.

Había realizado estudios de escultura en la Universidad de Tokio y además hizo algunos estudios de pintura que la llevaron a practicar una obra de fuertes y enérgicos trazos. Perteneció a un grupo muy activo de estudiantes de tendencias radicales y presentó varios de sus trabajos en el circuito de la Galería Naiqua, lugar de reunión de los amigos de Kubota, fundamentalmente de los que se movían en el circuito Hi-red, estructurado en 1963. La presentación de sus obras no obtuvo eco. El ambiente japonés de la época no estaba preparado para promocionar adecuadamente la obra de una mujer de tal impulso renovador, por ello tuvo que luchar por su independencia y reivindicar, como lo hizo Yoko Ono, su papel protagonista dentro del arte. 
En 1964 decide dejar Japón, y tras entrar en contacto con Maciunas, como ya hemos mencionado, se integra en Fluxus y contacta con Nam June Paik con el que se casará en 1977. Desde su llegada a Nueva York mantendrá su actividad como creadora de performances y arte conceptual de influencia duchampiana. Para poder sobrevivir sin renunciar a su actividad creadora llegará a trabajar como camarera con tal de no sucumbir y renunciar a sus ideales artísticos. En la década del 70 se convertirá en pionera de la video-escultura.

Desde el momento en que le conoció, mantuvo una excelente relación con Maciunas, con quien tuvo un trato diario, y pronto se integró en una de las comunas que éste organizó en uno de los antiguos edificios de Nueva York que había adquirido para alojar a los artistas de su entorno. Él estimó mucho a Shigeko y la incluyó sistemáticamente en las fiestas organizadas por Fluxus tanto en E.E.U.U. como en Europa. Nombró a Kubota vicepresidenta de Fluxus, reconociendo así el grado de implicación de la joven con las actividades del movimiento.

Muchas de las obras de la artista fueron producidas por Fluxus, como por ejemplo Flux Medicine que comenzó a editarse en 1966. Se trataba de cajas vacías de píldoras o envases de medicamentos que habían sido utilizados y consumidos por Maciunas. En algunas ediciones dentro del estuche aparecen fotografías de los medicamentos. Ella le dedicó la obra, que fue recibida por el artista enfermo con humor y entusiasmo (Hendicks, 1988: 307). Kubota hace referencia en esta obra a la obsesión de aquel por consumir medicamentos. Esta obra había que ponerla en relación con la de Maciunas Mystere Medicine (1964), pero teniendo en cuenta que responde a un concepto totalmente diferente.

Otra obra conocida que produjo igualmente Fluxus fue Flux Napkins (1967, aunque ya aparece en Fluxus Newsletter en 1965). Esta obra aparece firmada bajo el alias Loveko-Ai (nombre que parece ser que utilizó únicamente para esta obra) (Jacob, 1991: 15). Se hizo originalmente en una versión de 5 ejemplares de papel de servilleta y collages para las cenas fluxus organizadas por Maciunas en honor de Chieko Shiomi, Takako Saito, Nam June Paik y la propia Kubota.

Testimonio artístico de su afecto hacia Maciunas es el hecho de dedicarle distintos homenajes a través de su trayectoria artística, entre los que cabe destacar George Maciunas With Tow Eyes y George Maciunas One Eye (1976) obras 
en vídeo en las que aparece George recorriendo los edificios que había rehabilitado en el Soho neoyorquino en compañía de artistas y amigos.

En 1965 dedicó varias obras a la reflexión sobre el cuerpo y sus funciones. En la performance Vaginal Painting, creada para el Summer Perpetual Fluxus Festival, se presentó en el escenario, en cuclillas, sobre papel blanco extendido en el suelo. Inmediatamente comenzó a manchar el papel con una brocha, impregnada en pintura roja (metáfora de la propia sangre de la menstruación femenina), que se había cosido a la braguita. Para la época esta metáfora asociada a la pintura de acción era un reto y una provocación. Hacía público algo que se había mantenido como privado desde siempre, algo que incluso había sido considerado tabú para el hombre. El tema de la menstruación femenina, más que cualquier otro aspecto de los relacionados con los productos del cuerpo, había sido ocultado históricamente como si no tuviera lugar y habitualmente se aludía a ello con circunloquios y frases poético-sugerentes que sustituyeran la realidad que no quería ser visualizada. En la performance, Kubota asociaba el acto creativo-artístico con la capacidad de las mujeres para crear vida, pero lo hacía a través de la visibilidad de su indicador biológico. Una alusión tan cruda y directa rompía moldes en lo artístico, pero también en lo social. Tendrá que esperarse a la década del 70 para que obras como la instalación Menstruation Bathrom (1972) de Judy Chicago en la Womanhouse pongan en una evidencia de choque estos aspectos. Volverá más tarde sobre estos puntos de reflexión, cuando desarrolle su actividad como vídeo-artista.

Otra obra que tematizaba al cuerpo en este caso al humano tomado sin enfoque de género fue Calendar Playing Cards publicitado en 1966, y que nunca fue editada por Fluxus. Se trataba de un kit de cirugía que incluía un cuerpo humano de goma, con pulmones hinchables, corazón, estómago e intestinos.

En 1967 se casa con David Behrman, con el que será su primer marido hasta 1969. En ese mismo año conoce personalmente a Marcel Duchamp. La anécdota de cómo se produce el contacto resulta importante para explicar por qué Kubota dedica tantas y tales obras a Duchamp así como para comprender mejor el aspecto formal y el contenido temático de las mismas.

El marido de Kubota puso música al espectáculo de Merce Cunninghan Walk Around Time que se estrenó en Buffalo. Camino de Buffalo el vuelo en el que viajaba Kubota fue desviado hacia Rochester a causa de una tormenta de 
nieve desatada sobre las cataratas del Niagara. Eso le permitió no solo establecer contacto con Duchamp, quien también viajaba para asistir al acontecimiento, sino prolongarlo suficientemente como para que este encuentro marcara definitivamente su vida y su trayectoria artística. Obras posteriores de Kubota se referirán a aspectos relativos a este viaje. Es el caso de Meta-Marcel Window de 1976-77, que incluye imágenes de nieve alusivas a las condiciones meteorológicas del viaje. Esta serie dedicada a la reinterpretación del tema de las ventana de Duchamp continuará en varias versiones, incluso en años muy posteriores (1983 Flowers, 1991 Snow with computer writing, etc...). Lo mismo ocurre con obras como la escultura-instalación dedicada a las cataratas del Niágara (1985) y otras.

La referencia a Duchamp será recurrente en el desarrollo de la obra de Kubota, quien ya se interesó por su obra desde el momento en que conoció la obra de Marcel Desnudo Bajando la Escalera que despertó en ella una importante reflexión sobre el movimiento y el tiempo, aspectos que le interesaron durante toda su vida. Esto hará comprender su evolución. A partir de aquí la artista japonesa le dedicará gran número de obras como Desnudo Bajando una Escalera que es la presentación del movimiento real de una mujer desnuda -la realizadora cinematográfica Sheila Mac Clanghin bajando las escaleras del Anthology Film Archives de Nueva York (ubicado en uno de los lofts reorganizados por Maciunas). El vídeo materializa visualmente lo sugerido en el cuadro de Duchamp, por medio de cuatro escalones en los que se instalan cuatro monitores que reconstruyen la acción de descender. Kubota se apropia de la obra de su reconocido maestro para reinterpretarla en clave de vídeo. Las alusiones seguirán (Duchampiana 1976-77, Duchampiana Bicycle 1983, 1990, en distintas versiones).

Durante los ochenta además de reforzar su vinculación con Duchamp rebrotan sus raíces orientales aumentando sus cualidades contemplativas y las referencias a la naturaleza.

A lo largo de su trayectoria colaboró con otros artistas, en especial en su etapa más vinculada a Fluxus. Interpretó performances creadas por sus amigos. Una de esas participaciones fue su incorporación en Identical Luch de Alison Konwles y Philip Corner. Ella fue una de las comensales que intervenían tomándose el sandwich en aquella sencilla acción que revisaba el acto de co- 
mer. Ayudó constantemente a Maciunas en la organización y desarrollo de sus happenings y eventos, y trabajó con él en sus elaboraciones Mail Art.

Desde 1970 en que presentó Self-Portrait, (después incorporada como última parte de Vídeo Poema), ha experimentado continuamente con el lenguaje del vídeo, del que presentó en 1975 su primera Vídeo-Escultura (vídeo Chess) que incorpora un vídeo en el que aparecen imágenes de Duchamp y Cage jugando al ajedrez en 1968, empotrado en una escultura realizada en el 75. En este trabajo suma su preparación como escultora a la utilización del vídeo como medio artístico expresivo, lo que la convierte en una de las videoescultoras más importantes y a quien muchos consideran modelo de la nueva generación de artistas que utilizan el vídeo como lenguaje artístico. Kubota ha reivindicado la utilización del vídeo por parte de las mujeres artistas desde el momento en que comenzó a utilizarla en época bastante temprana, lo que ha hecho que se la considere una pionera del medio.

Ha elaborado algunas obras-manifiesto en este sentido como por ejemplo la conocida como Video is Victory of Vagina. El contenido que presenta el monitor metido en una bolsa de nylon colocada sobre un pedestal de madera transmite el mensaje "vídeo es la venganza de la vagina, el vídeo es la victoria de la vagina, el vídeo es la enfermedad venérea de los intelectuales, el vídeo es un apartamento vacío, el vídeo es la vacación del arte ¡viva el vídeo!”

Europe am 1/2 Inch a Day (1972) son treinta minutos de relato en vídeo en los que se recogen las vivencias que se obtienen en un viaje que se le ocurrió a Kubota al plantearse qué pasaría si realizara un viaje por Europa con una grabadora de vídeo portátil en vez de una tarjeta American Express.

Ella considera que la performance, la fotografía y la instalación han de ser medios que permitan a la mujer tener igual voz que la que hasta ahora han tenido los hombres y las corrientes dominantes en cultura.

\section{Alison Knowles.}

Una de las más importantes creadoras Fluxus fue Alison Knowles. Nacida en Nueva york, y graduada con premio en el Instituto de Bellas Artes Pratt de Brooklyn. Desde 1961 realizó performances, actividad por la que ha sido muy reconocida. Una de las primeras fue la titulada Shuffle en la que proponía que 
uno o varios performers se entremezclaran en la zona de la performance con el público, moviéndose por delante, por detrás, alrededor o a través de la audiencia, pero silenciosamente. En este caso los asistentes al evento son parte imprescindible, pero involuntaria de la acción.

Desde 1962 sus acciones y también sus obras objetuales toman como elemento central de investigación la comida o la forma de hacerla, es decir, tienen al acto de comer, o los alimentos, como objeto. En ese sentido encontramos su obra Proposition en la que el artista propone al público o performer improvisado, hacer una ensalada. Más tardía (1964) es su Variación numero 1 a Proposition, que subtitula Haz una sopa, o -en esos mismo años-, Bean Rolls (caja con papeles enrollados conteniendo textos y judías).

En otro orden de acciones, especial repercusión tuvo la performance Nivea Cream (noviembre 1962) en la que un primer performer entraba en la sala del Alle Scenen Theater de Copenhague, durante el Fluxus Festival, portando un tarro de Nivea Cream o un envase de crema de manos etiquetado como Nivea Cream. Ponía crema en sus manos y las masajeaba mientras se colocaba y permanecía ante un micrófono. A continuación, varios performers entraban uno a uno y realizaban la misma operación. Finalmente ellos se retiraban en el orden inverso al que habían entrado, en el momento en que el primer performer lo indicaba. Sobre esta performance se hizo alguna variación.

La tendencia fluxus a romper las barreras del ámbito artístico, sacando el arte a la calle y haciendo arte de la vida cotidiana, está en la raíz de Street Piece de 1962 en la que se insta, a quien quiera realizarla, a pasear por una calle, la obra puede ser materializada, o ejecutada como dirían otros, por aquel que manifieste el deseo de hacerlo. Es decir, lo que subyace es el concepto de que la obra no tiene por qué ser completada por el artista que la alumbra en su pensamiento y que cualquiera puede asumir ese papel dentro de un concepto de arte distinto al tradicional.

Ese mismo año concibe Color Music 1 for Dick Higgins que está dedicada al que era su marido desde 1960; en ella se solicita al espectador que elabore una lista de sus problemas numerándolos del uno al cinco. Se insta a que para cada problema se indique cual es la mejor solución que se pueda pensar; se pide que a cada problema se le otorgue un color y se aconseja que donde quiera que surja el problema se piense primero cual puede ser la mejor solución, y si 
no se puede hacer inmediatamente, hay que desviar su atención sobre el color, hasta que sienta la absoluta necesidad de intervenir.

También a Nam June Paik le dedica otra partitura para acción: Composition for Paik (1963), demostrando con ello las buenas relaciones que le unieron con el artista coreano. En ella se da al performer improvisado la indicación de que seleccione una plataforma o una zona cuadrada o rectangular, que mida el área, ayudándose de Paik, localizando su centro y que deje caer en este punto, desde el techo, una gota de plomo. Toda la operación tiene como finalidad la construcción de una plataforma para que Paik pueda sentarse en ella durante la performance. Acción que ya ha concluido en el momento en que se construye la plataforma, luego Paik nunca puede ver la performance desde allí, porque la performance es la selección y preparación en sí misma.

Participó en los eventos fluxus realizados en Wiesbaden en septiembre de 1962 desarrollando performances en los Fluxus Internationale Festspiele Nuester Music 14 Concerte. Así como en los seis conciertos del Festum Fluxorum de 1962 en Copenhague y en los de diciembre del 62 en París en el Centro de Estudiantes Americanos. Durante 1963 siguió colaborando en las acciones fluxus en Oslo (marzo), Amsterdam (Fluxus Festival) en el Hipokriterion Theatre y París de nuevo en el Fluxus Poesie Et Cetera. Anti-theatre. Sin dejar por ello de participar en otros eventos no organizados por el grupo, pero en los que los artistas vinculados a las performances intervenían aunque pertenecieran o fueran más cercanos a unos entornos que otros. A ello responde su inclusión en el Festival del Name en el que presentó Saldo de sombreros de Name8.

A finales de la década de los 60 Philip Corner compartió con ella un estudio en el que desarrolló la partitura de la performance Identical lunch (el almuerzo idéntico), en la que distintos performers comían en sucesivas ocasiones un sandwich. En este trabajo se ahonda como hicieron también otros miembros de Fluxus en la reflexión ya iniciada en los primeros años sesenta sobre las acciones que consideramos rutinarias e inapreciables, casi automáticas, para extraerles de esa banalidad y recuperarles tras su paso por el Zen, impregnados con otros sentidos: masticar, tragar, beber, etc..., así como las funciones que derivan de estos actos, como su evacuación y orina que están indisolublemente ligados al acto

${ }^{8}$ El Festival se desplegó a lo largo de un año completo, desde mayo de 1962 hasta mayo de 1963. En él intervinieron gran parte de los artistas del arte de acción (Goldberg, 1996: 133). 
nutricional, ponen así mismo en cuestión los márgenes del ámbito de lo estético y producen una reflexión que irradia hacia los límites del concepto asociados a la comida: la gula, el exceso y las relaciones rituales en la ceremonia de la alimentación. Un detenido proceso en el que repiensa y rehace el cómo, qué y con quien se come. Al tiempo el interés centrado en el gesto de la cara, la boca, etc..., que tienen protagonismo y se modifican en el acto del comer o los con él relacionados, que la vida diaria son gestos que realizamos inconscientemente. La performance que Dick Higgins amplió en algún aspecto relacional se convirtió en obsesivo para Philip Corner, quien investigó minuciosamente junto con Alison el almuerzo de sándwich de atún, pan de trigo tostado, lechuga y mantequilla sin mayonesa, y un vaso largo de leche o una taza de sopa ${ }^{9}$.

Junto a su actividad como creadora de performances, sus elaboraciones de objetos giran en muchas de sus obras, como ya dijimos arriba, en torno a los alimentos. En concreto hay uno que ha centrado gran parte de sus trabajos, me refiero a las judías (beans), mezcladas en muchas ocasiones con otros objetos. Entre las distintas presentaciones mencionaremos exclusivamente Bean Rolls (1963 y 1964), que consistía en cajas etiquetadas por Maciunas que contenían rollos de papel en los que se habían escrito textos. Sus pequeñas cajas conteniendo diversos objetos y en las que aparecían, o se mencionaban, las judías, continuarán produciéndose a lo largo de los $70^{10}$.

George Maciunas le brindó un homenaje a Alison a quien en el diagrama que elaboró en 1966 sobre Fluxus y la evolución de las artes consideró como una artista plenamente Fluxus, reuniendo judías y restos de otras ediciones de Beans Rolls en el Bean Kit editado por Fluxus en 1964.

A ella le dedicó Ben Vautier su Music by Alison, ejecutada por Ben y la propia artista durante el Fluxus Street Theatre, como parte del Fully Garanteed, 12 Fluxux Concerts, también denominado Flux Festival en el Fluxhall de Nueva York (mayo de 1964).

Knowless ha desempeñado de 1964 hasta 1970 una tarea importante como editora especial en la editorial que por su iniciativa Dick Higgins denominó

\footnotetext{
9 Sobre este tema véase L'Esprit de Fluxus, 1994: 220; Ruhe, 1979; y Sichel, 2002: 183, 185, 187).

10 Sobre distintas versiones de Bean Rolls y otras obras de Knowles editadas por Fluxus véase Hendrick, 1988: 299 y ss).
} 
Else Press. Igualmente ha sido cofundadora junto con Higgins de Printed Editions Publishing Creative (Fluxus, Galerie Schüppenhauer, Köln, 1992).

Como la práctica totalidad de las artistas del grupo, y quizás más que ninguna otra, colaboró continuamente en la materialización de acciones concebidas por otras y otros artistas; de esta amplia actividad únicamente mencionaré Solo for Voice n⿳o 2 de J. Cage en octubre de 1962, pero sin dejar de insistir en su capacidad para trabajar en colaboración con otros. Su obra Glove to be worn while examining nos introduce en la reflexión sobre la visita al ginecólogo o sobre la utilización de una sonda anal. Igualmente se preocupa en Child art piece (1962) en la que se proponen acciones cotidianas con los niños de las parejas que quieren realizarlas.

Sus revisiones de los roles y acciones que siempre se han destinado a la mujer, su reflexión sobre la cuestión femenina y la redefinición del cuerpo le llevará a continuar en la reivindicación e incluso profundizar en ella, como en el caso de la creación de su House of Dust, su gran casa útero de fibra de cristal como un escenario y un telón de fondo para acciones y eventos.

En la diáspora de los 70 Alison Knowles se convirtió en Profesora Asociada (Assistant Professor of Art) y directora del laboratorio gráfico del California Institute of Arts. Ha continuado durante las últimas décadas realizando performances por todo el mundo y trabajando en medios sonoros, escritos así como realizando obras de arte visual.

\section{Kate Millet.}

La estadounidense Kate Millet (1934) había estudiado en la Universidad de Minnesota y en Oxford. Su actividad como escultora fue lo que le llevó en 1961 a viajar a Japón para exponer. Allí se abrió a la cultura japonesa y contrajo matrimonio con Fumio Yoshimura.

Junto a su trabajo como escultora hay que señalar también que produjo y realizó un film, montado en Londres, de 70 minutos, compartiendo con Sybil, Robin y Rodha su actividad como directora, experiencia que le produjo un profundo desaliento ante la incomprensión de los productores profesionales de Nueva York, y que la llevó a sufrir las tensiones entre las tres mujeres que desnudaban su vida a lo largo de la película (Millet, 1990: 28-29). 
Su vinculación con Fluxus se vio obstaculizada por el especial talante de Maciunas, que no aceptó con agrado la trayectoria de reivindicación feminista de Kate. El enfrentamiento culminó con la excomunión lanzada por Maciunas contra Millet.

Maciunas se planteó en varias ocasiones editar entre los productos Fluxus algunas de las obras de Kate y efectivamente en el Boletín del movimiento (Flux newsletter) aparecen noticias en varias ocasiones referidas a obras realizadas por ella. Como ocurre en el caso de Cabinet de 1967 que fue considerada como un flux-project, aunque nunca se llegó a editar como tal, o Table que había sido presentada en la exhibición que la artista hizo en la Judson Gallery, donde fue vista por Maciunas que quiso hacer una edición Fluxus de la misma (Hendrick, 1988: 405) y por ello, se anunció en ese mismo boletín de 8 de marzo, igualmente como un fluxus project, pero que nunca llegó a editarse como tal. Ni siquiera editó, a pesar de su interés por la obra, el taburete (Stool) que Kate Millet había presentado en 1966 en la Hudson Gallery, con pies de aspecto humano y zapatos, finalmente los pocos ejemplares que se hicieron de esta lúdica pieza fueron realizados por la propia Kate.

El gran proyecto de Kate Millet Dinner Ware, del que ella misma realizó un prototipo, fue anunciada sistemáticamente como fluxus project desde 1967 y se incluyó en las listas de productos Fluxus realizados en el periodo1961-69 (o 1961-1970, como figura otras veces). Sin embargo, parece ser que a pesar de que en alguna ocasión piezas relacionadas con esta obra aparecen con precio, no llegaron a producirse comercialmente. El diseño de platos y tazas desechables de Kate Millet que ha sido considerada en el ámbito de su posicionamiento de género, parece que llegó a formar parte del proyecto de Maciunas Implosion Inc., por medio del cual pretendía sacar, en colaboración con Bob Watts y Herman Fine, productos Fluxus al circuito comercial. (Flux Newsletter 1967), a pesar de eso no llegaron a ser producidos en versión masiva. Tampoco verán la luz como ediciones Fluxus otras piezas relacionadas con su mesa dispuesta, en la que se ha querido ver un antecedente de la Dinner Party de Judy Chicago (L'Esprit de Fluxus, 1994: 217).

Durante los años 60 apoyó las distintas causas de la libertad. Fue activa pacifista, oponiéndose frontalmente a la guerra de Vietnam y situándose contra el racismo y la discriminación, allá donde se produjera. Su feminismo se 
orienta desde un antisexismo. Formó parte sustantiva del Women's Lib, aunque fue expulsada más tarde del movimiento feminista por su individualismo. Se enfrentó con la tendencia igualitarista del grupo, que defendía el anonimato y el poder de decisión sobre los escritos individuales de las integrantes del movimiento ${ }^{11}$.

Su posición pacifista llevó a Kate a enfrentarse con algunos de los sectores más radicales del movimiento feminista, sabiendo que su alineamiento contra todo tipo de violencia no era bien aceptado en los momentos en que ella lo planteó durante la Reunión sobre la No Violencia en Nueva York. Ella misma relatará más tarde sus dudas, o incluso su miedo al rechazo, por hacer esta declaración de principios con posterioridad a que la revista Time hubiera publicado su orientación sexual. Hoy quiero confesar algo que es menos aceptable todavía desde el punto de vista social. Soy pacifista (Millet, 1990: 479).

Su intervención se opone a la declaración de Martha Shelley, que afirmaba su alineamiento con la violencia, para conseguir los derechos de la mujer. Millet apoya su teoría en la convicción de que la violencia en la persona surge de una infancia dolorosa, que a su vez ha sufrido la violencia: la raíz es la violencia ejercida sobre los niños, es la primera marca que hace posible la guerra y cualquier otra atrocidad parecida (Millet; 1990: 480).

Llevando esto al terreno político, Millet se sitúa frente aquellas que se proponen alcanzar una nueva sociedad a través de la violencia: con el primer acto de crueldad cometido en nombre de la revolución, con el primer asesinato, con la primera purga o la primera ejecución, hemos perdido la revolución (Millet, 1990: 480). Estas palabras provocaron un enfrentamiento en un núcleo fuertemente asentado en la ruptura. Sin embargo Millet les abre una nueva posibilidad:

la política es repetición. No es cambio. Cambio es algo que está más allá de lo que llamamos política. El cambio es la esencia, la política se supone que es el instrumento para lograrlo. Preconizar el cambio es preconizar el fin de la violencia de toda clase (Millet, 1990: 480-481).

Como mujeres ya hemos comenzado a desarrollar una nueva dinámica social, hemos desafiado la jerarquía tradicional del lugar y del rango en las reuniones, las nociones convencionales de liderazgo, de autoridad y de talento. Mucho

${ }^{11}$ Lidia Falcón. “Pórtico". En pleno vuelo de Kate Millet, pp. 12-13. 
más, estamos desafiando la división tradicional entre lo público y lo privado, esas categorías segregadas de la vida que heredamos del pasado. Al descubrir la integridad vital de la experiencia humana hemos eliminado estas distinciones artificiales. Así estamos forjando una nueva política [...] debemos crear un nuevo método para la conducta de la vida humana (Millet, 1990: 481).

En el periodo de colaboración con Fluxus, ella estaba trabajando en el que en 1969 sería su libro Sexual Politics ${ }^{12}$ trabajo de investigación presentado en la Universidad de Columbia. En el texto se proclama la tesis de Millet de que el sexo reviste un cariz político que, las más de las veces, suele pasar inadvertido. Para demostrarlo trabaja con la función que desempeñan conceptos como poder y dominación en algunas descripciones de la actividad sexual ofrecidas por la literatura contemporánea.

Su análisis de la relación social que existe entre los sexos quiere configurar una visión global del patriarcado considerado como institución política, para ello asume el análisis de las relaciones sexuales tradicionales que se desarrolló durante el siglo XIX y los inicios del XX, centrándose después en el periodo de paso de las orientaciones revolucionarias al de clima reaccionario que se implantó a continuación. Todo ello le lleva a revisar históricamente ese periodo y centrándose en tres escritores de esa época (Lawrence, Miller y Mailer). Cerrando con el acercamiento a la obra de J. Genet, al que abordó por contraponerle a Mailer, y con cuya perspectiva se identificará parcialmente como parece desprenderse de las declaraciones efectuadas por Millet a la revista Time, en el número en el que aparece el retrato de la propia Kate en la portada ${ }^{13}$. En aquellas declaraciones confesó abiertamente su lesbianismo, Genet, por su parte, filtraba a través del prisma homoerótico la jerarquía sexual. Mailer había arremetido precisamente contra el tabú de la homosexualidad (Millet, 1995: 607). En sus obras se deja ver la necesidad de erradicar esa opresión como primer paso imprescindible para el cumplimiento de un programa auténticamente revolucionario:

A este respecto, el mayor empuje debe derivar de una verdadera reeducación y maduración de la personalidad, y no tanto del despliegue teatral de la agitación armada (aun cuando éste se hiciese inevitable)... (...) modificar cualitativamente

12 Edición en español: Política sexual, Cátedra, Madrid, 1995.

${ }^{13}$ Retrato realizado por Alice Neil. 
el modo de vida equivale a transformar la personalidad, lo cual supone una liberación de la humanidad respecto de la tiranía ejercida por las castas económicas, raciales y sexuales, por la adecuación a los estereotipos de naturaleza sexual (Millet, 1995: 609).

En 1978 funda la colonia de arte feminista The Farm ${ }^{14}$. Kate Millet también ha escrito Sita y Prostitution papers, The Basement: Meditations on a Human Sacrifice.

En 1997 se hizo una exposición antológica de su obra escultórica en la galería de Bellas Artes de la Universidad de Meryland, Baltimore Country, en la que se presentaron obras que reflejaban su visión de la escultura desde etapas tempranas. Las obras que corresponden al periodo más cercano a Fluxus evidencian sus preocupaciones sobre la mujer, el cuerpo y el sufrimiento. Sus esculturas instalaciones en las que la mujer parece atrapada o perdida concilian con su posicionamiento sin transformarse en meros vehículos explícitos de su teoría.

\section{Mieko (Chieko) Shiomi.}

Cuando Chieko Shiomi acepta la invitación de Maciunas para formar parte de Fluxus en 1964, lleva ya tras de sí una interesante trayectoria. Había seguido estudios musicales en la Universidad Nacional de Tokio. Más tarde se vincularía a la música experimental, lo que la llevó a ser miembro fundador del grupo Ongaku al que ya hemos mencionado al revisar la obra de Kubota. En Japón había desarrollado ya una intensa actividad vinculada a la performance. De 1963 son algunos de sus eventos más sencillos, entre los que destaca Música Viento. Su partitura indica lo siguiente: Levanta viento/ Déjate llevar por el viento/ Viento en la playa/ Viento en la calle/ Viento levantado por un cochel Tifón.

Otra pieza de gran simplicidad, en línea por tanto de las acciones de influencia Zen que tanto entusiasmaron a los Fluxus, es Shadow cuyas instrucciones para la performer dicen así: Haz sombras -inmóviles o en movimiento- de tu cuerpo en el suelo, en la pared o en la carretera o sobre cualquier cosa. Coge las sombras por algún medio.

\footnotetext{
${ }^{14}$ Sobre este aspecto se puede consultar Anne B. Keating (1995): A world we have invented here: Exploring community, identity Art $y$ the construction of "The Farm" Kate Millet's Feminist Art Colony, 1978-1994. University of Meryland College Park.
} 
La performance más sencilla es quizá Música para Dos Instrumentistas del mismo año. Obra que es un antecedente muy directo de performances desarrolladas por otros artistas en la década de los 70, y aludo en este punto a trabajos como los de Marina Abramovic y Ulay. Shiomi da unas mínimas instrucciones: En una habitación cerrada pasa dos horas en silencio. Se puede hacer cualquier cosa menos hablar. La valoración Zen del silencio es aquí evidente.

La última obra de esta etapa a la que haré alusión es Mirror (Espejo). Para materializar la acción las indicaciones nos llevan a una playa arenosa y se nos insta a situarnos de espaldas al mar, a continuación se ha de coger un espejo, colocárnoslo ante la cara y mirar en él. Después se indica que caminemos hacia atrás y que nos metamos en el agua.

La vinculación con la iconografía de la mujer-Venus ante el espejo y la relación Venus-mujer con el mar está clara; sin embargo, aquí se invierte el desarrollo secuencial. La mujer se mete en el agua, no surge de ella. No obstante Shiomi no indica expresamente en la partitura que quien desarrolle la acción haya de ser mujer, aunque al realizarlo ella misma esta interpretación adquiere sentido. Se ha interpretado este evento como una remisión a Simone de Beauvoir en el Segundo Sexo en la que se presenta a la mujer como observadora de sí misma, que refleja como un espejo formaciones culturales.

A su llegada a Nueva York, Shiomi fue muy bien acogida por Maciunas así como por el resto de los componentes del grupo. En cualquier caso, Shiomi no habría de sentirse sola, junto a ella estaba Kubota. También Yoko Ono y los demás miembros de origen oriental que no eran pocos, contribuyeron a profundizar la familiaridad con formas de pensamiento y orientaciones culturales diferentes y a facilitar la integración. Maciunas valoró sus nuevas composiciones y se decidió a apoyar y editar sus obras.

Del año de su ingreso en Fluxus es la segunda versión de Shadow, (Shadow II) en la que se propone proyectar una sombra en la otra parte de la página, observar la línea de contorno entre la sombra y la zona iluminada y finalmente se pide, a quien esté ejecutando la acción, que se transforme en la línea de contorno.

Uno de los eventos más conocidos de esta etapa fue Air Event presentado en la Square Gallery de Washington durante la Fluxfest de ese mismo año y de cuya realización existe documentación fotográfica de Peter Moore, quien fil- 
mó también gran parte de la serie de los fluxfilms. La partitura de la acción indica inflar un pequeño globo de goma haciéndolo de una sola vez, firmar en la superficie del globo con lo cual el globo se convierte en el pulmón de quién lo infló. Finalmente, se da la posibilidad de comprar en subasta los pulmones de otros performers.

Acciones sencillas, vinculadas a lo lúdico que reconsideran como en este caso aspectos vinculados al cuerpo, pero también sobre el valor de la obra artística como objeto. Se ha especulado con el posible conocimiento de la obra de Piero Manzoni Air Sculpture que consistía en un globo conteniendo la respiración del artista.

En la misma galería presentó Shiomi su Disappearing Music for Face también documentada por Peter Moore. En ella se presentaba ante el público durante la transformación de su cara desde la expresión de una sonrisa hasta el cese de la misma. La sencillez y simplicidad de la acción es de las más significativas en el conjunto de las obras fluxus y coincide plenamente con la orientación de Cage. Como ya hemos señalado Yoko Ono quiso filmar una obra parecida y Maciunas por respeto a la obra de Shiomi no se lo permitió. Ono hizo, dejando filmar su rostro (en realidad exclusivamente su boca y barbilla), la obra de Chieko, respetando la autoría de esta. Al final Ono reconoció la diferencia entre el planteamiento de su propuesta y el de Chieko Shiomi. No obstante, para la edición del film Maciunas colocó como etiqueta una fotografía con sucesivas exposiciones del propio rostro de Chieko Shiomi pasando de la sonrisa a la seriedad.

En aquel año hizo también Photo Event for Two Players, en el que se trata de tomar fotografías de cuerpo entero y de partes concretas del perfomer con el que se forma pareja respectivamente, pero con la particularidad de que se hace de forma sucesiva y el segundo performer debe utilizar la película ya expuesta por el primero. El interés por la fotografía también fue compartido por algún otro miembro de Fluxus y la propia Yoko lo utilizó como motivo en fragmentos del film Imagine más tarde.

Sin embargo de la década del 60 las obras de mayor repercusión son Game Aroun a revolving Door juego con instrucciones (reglas y método de juego) en 
inglés e italiano realizado en formato poster, de $1967^{15}$ y las distintas versiones de Spatial Poem. En la primera, Word event, de 1965 se requiere la intervención de varios participantes, los cuales no tienen por qué estar presentes a la vez en el mismo lugar. En ella se requiere que cada uno de los participantes escriba una o varias palabras en una tarjeta, ha de hacerse saber a Chieko la palabra o frase y el lugar donde la coloca, para que ella haga una distribución en el mapa del mundo que será enviada a cada participante ${ }^{16}$. Esa distribución la hacía Shiomi colocando los textos escritos en tarjetas que tenían incorporados alfileres que permitían pincharlas a modo de banderitas sobre el mapa en el lugar correspondiente.

En Spatial Poem $n^{\underline{o}} 2$ se encuesta sobre qué lugar de los enumerados en un escrito era hacia el que la persona que recibía el texto se dirige en la fecha y hora que se señala, por ejemplo:

N. York 5:00 pm, Oct. 15. 1965

Amsterdam 11:00 pm, Oct 15. 1965

Barcelona 11:00 pm, Oct 15. 1965

Irán 1: 30 am, Oct 16.1965 etc...

Así hasta 26 ubicaciones simultaneas, como mínimo. Se solicita que el texto se escriba en letra de imprenta o a máquina.

En sucesivos Spatial Poems $n^{0} 4$ y $n^{-0} 5$ creados en 1971 y 72 respectivamente, se solicita realizar mínimas acciones (hacer sombras con cartulinas sobre cualquier lugar o abrir cualquier cosa que esté cerrada) y comunicarlas por escrito a la artista dando datos de cómo y durante cuánto tiempo se realizan. Las instrucciones sin embargo, fijaban la fecha en que debía realizarse la acción.

Todos estos trabajos se incluyen plenamente en la tendencia Mail Art que fue bastante frecuentada por Maciunas y otras artistas del Fluxus, incluida Kubota en alguna de sus realizaciones. Con ello se refuerza la raíz que enlaza con investigaciones que en este sentido inauguraron los futuristas y al tiempo

\footnotetext{
${ }^{15}$ Conviene señalar que la versión recogida por Ubi Fluxus aparece datada en 1967, aunque en Happening and Fluxus (1970) aparece la fecha de 1968 para la edición de Milán.

${ }_{16}$ Versión recogida en Happening and Fluxus. Belnischer Kunstvenin 1970, la versión recogida por la obra Ubi Fluxus Ibi Motus no recoge el anuncio del envío a todo.
} 
desarrolla el deseo de disolución de obra de arte como objeto y la vinculación con el texto escrito y con la acción derivada o en relación con el mismo.

\section{Takako Saito.}

Desde 1964 pertenece al grupo Fluxus, aunque llevaba en Nueva York desde el 63, donde contactó con Maciunas y Ay-o. Allí permaneció hasta el 68 en que viaja a Francia (1968-72), Inglaterra donde permanece desde el 72 hasta 1975 e Italia del 75 a 1979, alternando sus estancias y su trabajo en Europa con viajes a Japón hasta que en el año 78 se instala definitivamente en Düsseldorf, en donde ha continuado trabajando ya de manera permanente.

Su preparación universitaria, que se había complementado con estudios de psicología infantil en la Universidad femenina de Japón, le permitió una buena conexión con el arte conceptual, y concilia bien con su tendencia a la simplicidad y al aspecto lúdico de sus tratamientos artísticos. Ella ha sabido equilibrar siempre su actividad creativa con su vinculación al mundo de la educación y la enseñanza. Antes de formar parte de Fluxus participó en el movimiento Creative Art Education desde 1952 hasta 1960. Fue en este tiempo cuando conoció a Ay-o (1953), lo que la facilitó posteriormente su contacto con Maciunas.

Con posterioridad a la etapa de mayor implicación en el entorno Fluxus ha venido compartiendo su trabajo como profesora en diversas escuelas de arte con la realización de sus trabajos artísticos.

Junto a sus concepciones de eventos y las materializaciones de sus performances-happenings también destacan las creaciones de cajas lúdicas y juegos, siendo estos últimos lo más conocido, o al menos lo más difundido a través de la bibliografía. Son obras en las que las piezas del ajedrez o de las damas se sustituyen por botellas, copas de vino, frasquitos de perfume $\mathrm{u}$ otros objetos como cajas plásticas (1965), bloques de madera (1965), especias (1965) trabajos de este tipo son cíclicos en su trayectoria. Su ajedrez con distintos pesos ocultos dentro de las piezas, fue puesto en acto por YoKo Ono y realizado por Takako en 17 versiones firmadas y numeradas.

Otros juegos se presentan como una cartulina (Game $n^{-0}$ 101/200) que contiene 8 juegos diferentes. La cubierta es un juego con una cabeza humana con la palabra Games sobre ella. 
En sus propuestas para acciones, sus notas de instrucciones son muy breves y de contenido muy simple. Como ejemplo simplemente mencionaremos la que indica Haga 300 agujeros con cualquier instrumento: este es mi regalo (1964).

En sus performances daba valor a lo aportado por el azar e incluso por la iniciativa del público, viendo en ello una manifestación vicaria del azar. En este caso el público no actúa como mero espectador pasivo, de ahí que en ocasiones se hable de performances interactivas, $\mathrm{u}$ otros lo vean como una forma de happening. Como muestra de esta forma de hacer recordaré una de estas acciones realizada en Milán y recogida en el texto de Michel Giroud (Fluxus y Dino di Maggio..., 1998: 32):

Al principio de la representación, repartía flores al público, entonces Joe Jones y yo jugábamos con los cubos (...) los cortamos con tijeras y un cigarro. Cuando nosotros estábamos jugando con los cubos en el suelo, se nos unió mucha gente. Dejé de jugar me apoyé contra la pared y observé a la gente. Entonces alguien de entre el público vino con las flores y empezó a colgarlas. Después mucha gente vino a colgarlas. Lo que ocurrió fue algo realmente inesperado y bello.

\section{Bici Forbes (Hendricks).}

Norteamericana que estudia edición, producción, y postproducción cinematográfica. Bici realizó durante su conexión a Fluxus obras que adelantan el interés por el mundo de la comida como elemento visual o de concentración socio-ritual que le acerca a otras obras del grupo como las de Alison Knowles. En este área de trabajos hay que mencionar Colored Bread (1969) en el que se ha querido ver la influencia de Man Ray, en su trabajo Pun with loaf of french bread. Este trabajo está relacionado con sus Black monomeal y con white monomeal que aparecen en la misma publicación, Exit1, impreso en Flux Fest Kit2.

Publicó también gran cantidad de trabajos propios de orientación Fluxus desde 1965. Su colaboración con el movimiento se materializó no sólo en la orientación de sus obras, sino también a través de la colaboración con Maciunas en la concepción de trabajos conjuntos.

Otra obra destacable es Defrost the american flag, una bandera americana congelada en un bloque de hielo, un alegato político contra la guerra de Vietnam. 
Además de estos trabajos realizó obra en 16 y $35 \mathrm{~mm}$ y ha trabajado con mucha frecuencia en el campo de la edición de textos escritos. Su interés por los trabajos interdisciplinares la movió a fundar en 1965 el Black Thumb Press de New York con la intención de editar en su seno trabajos de esa índole. Entre ellos destacan Punctuation Poems (1966), Language box box language (box with cards) (1966). Igualmente cabe destacar eventos como Sky event o Water event (en Film culture no 43 editado por Jonas Mecas, Nueva York, 1966).

\section{Annie Vautier.}

Fue otra de las colaboradoras del grupo, aunque en las fuentes de Fluxus se la menciona poco y de la que es difícil lograr información e incluso cuando se encuentra aparece en algún caso vinculada el entorno de Ben (Benjamin) Vautier (Flux Codex, pp. 493-494). En la época de mayor relación con los artistas cercanos a Maciunas, su arte de concepto le llevo a realizar Flux Mobile una obra en la que se fusionan la presentación de una a modo de instalación con la realización de una sencilla performance. La instalación se componía de plantas en macetas y jarrones distribuidas en la galería y la performance consistía en regarlas cada tarde del periodo en que duraba la exposición (7-13 diciembre). Annie advertía en la tarjeta de invitación que las flores que componían la obra no estaban a la venta por si su planteamiento simbólico no era entendido en primera instancia por el visitante. Maciunas estaba preparando etiquetas para editar Flux Mobile y así lo refleja en varias cartas dirigidas a Ben Vautier, esposo de Annie, sin embargo, nunca llego a hacerlo.

Otra conocida obra conceptual de Annie Vautier ha sido Sweets (bombones). Se trata de una instrucción considerada como partitura indicada para un concierto fluxus. La instrucción pide que se distribuyan bombones entre el público para que se produzca un sonido al frotar los papeles de los envoltorios. Como en muchos trabajos fluxus el público es quien ha de materializar la obra concebida por el artista.

\section{Daniela Palazzoli.}

La italiana Daniela Palazzoli, se vinculó a las actividades Fluxus en su propio país. Se relacionó especialmente con Maciunas. En el ámbito creativo se ciñe fundamentalmente al mundo de la performance. Su labor como histo- 
riadora y crítica de arte es hoy su faceta más conocida, aunque no la única, pues su interés por el mundo del arte la ha llevado a organizar exposiciones, así como otros tipos de manifestaciones artísticas.

Interesada especialmente en el mundo de la fotografía, ha investigado en este entorno no sólo en su aspecto histórico, sino en su desarrollo dentro del marco de las nuevas tecnologías.

Es también docente en el sector de la comunicación social. De entre sus publicaciones (ha publicado un magazine y varias series de posters en colaboración con G.E. Simonetti), destacan sus catálogos -dedicados a figuras como Ben Shan, Edward Muybridge, Henry Cartier-Breson o Man Ray entre otros-, y sus libros. Los más conocidos son Fotografía, cine y videotipe (Milano, Fabri, 1972), y Il sentimento del 2000, Arte e Foto 1960/ 2000 (Electa, Milano, 1999).

\section{Mary Bauermeister.}

Provenía del mundo del diseño, había estudiado en la escuela de diseño de Ulm (Alemania) en los años en que estaba dirigida por Max Bill (1954-5) y más tarde en la Escuela de Arte de Saarbrüken. Desde 1957 instaló su taller en Colonia. Allí comenzó a relacionarse con Paik, Cage, Tudor, La Monte Young y otros con los que colaboró en la organización de conciertos y happenings. En 1961 siguió un cuso de composición de nueva música con Karlheinz Stockhausen en Darmstad.

A comienzos de 1962 se trasladó con Stockhausen al sur de Sicilia y allí se dedicó a la pintura, mientras él componía. Su relación de pareja resultó fértil para ambos. Ella aportó ductilidad a las rígidas estructuras de Karlheinz y por influencia de este, Mary aprendió a respetar más lo estructural y lo formal.

Tras el Festival Fluxus organizado por Maciunas en Wiesbaden, Mary Bauermeister decide trasladarse a Nueva York en donde se incrementan sus relaciones con artistas de vanguardia y en especial con Fluxus. Su colaboración con Stockhausen, sin embargo, no sería bien comprendida por Maciunas. En 1963 aquel presentó una versión de su obra Originale en el primer New York Avant-Garde Festival organizado por Charlotte Moorman. La performance estaba dirigida por Kaprow e intervenía también en ella Paik. Maciunas junto con Takako Saito, Ay-o, Flynt y otros, se manifestó en contra de la obra 
por considerarla como un ejemplo de "imperialismo cultural" extranjero (Goldberg, 1996: 133) y una demente combinación de azar y estructura.

M. Bauermeister ha seguido colaborando con Stockhausen, con quien tuvo dos hijos, en obras como Plus-Minus, y realizando obras creadas individualmente. Junto a la pintura y el grabado ha cultivado el arte intermedia como es habitual también entre los que han sido en algún momento miembros o simpatizantes de Fluxus.

\section{Alice Hutchins.}

La californiana Alice Hutchins, que provenía del campo de la pintura, aunque había realizado sus estudios de Historia y Economía en la Universidad de Berckeley, se instala desde 1950 en París, después de haber vivido en distintas ciudades americanas, así como en El Cairo. Allí comienza su acercamiento a la pintura en el estudio del pintor y cineasta Robert Lapoujade.

Desde 1967 abandona la pintura y comienza sus experimentos con imanes metales imantados. Deja sus dibujos lineales-horizontales que deseaba transformar en formas tridimensionales y pasa directamente a ellas al utilizar los pequeños magnetos que compraba en unos almacenes de Hardware, lo que le permite trabajar tridimensionalmente sin tener que aprender las técnicas de escultura (Ruhe, 1979).

Por otro lado eso permite que la disposición presentada en las obras pueda ser modificada por el propio público visitante. Ella presenta los materiales dentro de una caja de plástico y los espectadores no sólo pueden cambiar la disposición de los componentes dentro de la caja, sino elaborar con ellos un objeto, si así lo desean. El componente lúdico y creativo hace la experiencia gratificadora. A estos elementos metálicos a los que no encontraba nombre para denominarles les llamó play-things: fragmentos metálicos que pueden ser tocados de manera exploratoria hasta llegar a constituir un nuevo objetoconstrucción. Esto abrió para Hutchins una vía por la que relajar y ampliar el marco mental del espectador creativo.

Su vinculación a Fluxus le llevó también a hacer incursión en la poesía visual. En alguno de sus trabajos combina la utilización de las cajas con textos incorporados en postales escritas, en la que parece advertirse una relación con 
las obras de Mieko (Chieko) Shiomi. Alice Hutchins ha participado en numerosas exposiciones convocadas por asociaciones de mujeres, como por ejemplo Grandes Femmes, Petits Formats (París, Iris Clert Galerie, 1974). En 1975 participó en Color Light and Image en el Women's Inter Art Center de Nueva York, promovida por L'Union de femmes Peintures-Sculpteurs de París, que a su vez organizó Bijoux, Caillous, Fous en 1980 y en la que Alice participó igualmente.

\section{Anne Tardos.}

Estudió pintura, escultura y cinematografía, lo que le permitió trabajar en experimentación intermedia en el que se incluye la manipulación de todo tipo de imágenes, tanto procedentes de dibujos -o de otras expresiones plásticascomo videográficas y por ordenador.

Desde 1966 se afinca establemente en Nueva York. Hasta ese momento había vivido en distintos lugares de Europa. De Cannes (Francia) se trasladó con su familia primero a Budapest y más tarde a Viena.

En los años sesenta colaboró en algunas performances de Jackson Mac Low (1960) y de Emmet Williams (1963).

En 1970 realizó una película sobre 365 caras de personas, perros y gatos que fue rodada en las calles de Nueva York y en Central Park, los interiores se rodaron en el propio apartamento de Anne.

Más tarde hizo otras en las que aparecían varias personas realizando una serie de acciones simples como por ejemplo comer manzanas (Video instalación Apple Eaters, 1973), en una orientación que la hace en parte relacionarse con algunos trabajos de Yoko Ono y algunos otros miembros de Fluxus. En esta línea habría que situar Pipes at 110 Mercer, November 1974, en el que se graban los sonidos que en esa fecha y lugar producían las tuberías. Similar es el caso del trabajo que consistió en grabar el sonido producido por las gotas de agua que caían sobre una plancha de metal en el interior del refrigerador de su apartamento al descongelarse: Refrigerator Defrosting (1975). En algún caso su planteamiento se relaciona con el happening como en el tratamiento dado al banquete del Festival Vegetariano (1975) en el que se invita a la audiencia a participar en la consumición de la comida que había sido previamente preparada. 
Su buena relación con Maciunas se ha materializado en algunas ocasiones como en el caso de la realización de un "retrato" del lituano con base en vídeo, pero realizado con un sistema de trabajo que fue muy frecuente en sus obras del periodo de la década de los 70 y comienzos de los 80: Portrait of George Maciunas via video by Anna Tardos. A la proyección del vídeo realiza una serie de fotografías del propio monitor mientras manipulaba la cinta (Ubi Fluxus Ibi Motus, p. 371). De los trabajos En Memoria de John Cage existen varias versiones en acrílico y collage. Igualmente en relación con esto se realiza un álbum discográfico en homenaje sonoro a Cage titulado: A Chance Operation: The J. Cage Tribute (1992) en el que se incluyen fotografías de John Cage; Anne y Mac Low ponen las voces y la percusión.

En la década del 90 ha publicado varios libros Uxudo Mayg-shem Fish y Cat Licked the Garlic, en los que presenta obras y textos en varias lenguas y utiliza gráficos e incluso en alguno de ellos (Licked) se añade un vídeo.

Ha colaborado en innumerables ocasiones y en distintos tipos de obras con Jackson Maclow, con el que se casó, y con otros artistas como en el vídeo Statues (1977/1999) rodado por Anne y realizado en colaboración con Simone Fortí que desarrolla en él su trabajo de danza.

De entre sus obras hay dos que merecen especial mención Kinder Born Children (1984) y Territorial Demarcation (1974). Esta última consistió en la presentación de una construcción plástica: un orinal femenino del que salían diez tubos en círculo que deletreaban en plástico transparente el nombre de la autora. Se invitó exclusivamente a las mujeres a participar para demarcar su lugar entre los hombres (Ubi Fluxus Ibi Motus, p. 371).

\section{Carla Liss.}

Desarrolló una actividad fluxus a partir de 1968, poco después de su llegada a Nueva York (1967) a donde se traslada desde su ciudad natal Hollywood. Sus trabajos están muy vinculados al mundo del cine, no obstante realiza también otra serie de obras conceptuales.

Island Flux Souvenir (1972) recoge una serie de elementos que sirven de recordatorio del viaje realizado por un grupo de artistas fluxus a una isla del Caribe (Isla Ginger) con la idea de hacerla autosuficiente y convertirla en 
propiedad colectiva. El viaje resultó un fracaso. Aislados, sin comunicación con el exterior -Maciunas quedó con el piloto que les había llevado a la isla en que les recogería al cabo de una semana- y sin agua, terminaron siendo atacados por la fiebre causada por la savia venenosa de los árboles bajo los cuales dormían. En relación con este viaje y su recuerdo está la obra Travel Fluxkit (producido a lo largo de varios años pero iniciado en 1972) en el que se introducen tickets usados, horarios, etc..., y para el cual diseñó Maciunas una etiqueta. En Island Flux Souvenir también se recogen reproducidos los planes de viaje para dar la vuelta al mundo en un barco dragaminas con la intención de parar en el mayor número posible de islas, teniendo en cuenta que a Maciunas le entusiasmaban.

Otro trabajo que mereció la atención de Maciunas y por tanto se incluyó en las listas que este elaboraba sobre los productos Fluxus y además se le mencionó varias veces en el Fluxnewsletter (boletín de noticias), fue Sacrament fluxkit, que se venía realizando desde 1961 y aún aparece mencionado en la lista de 1976. Consistía en una colección de aguas de diversas fuentes que supuestamente debían ser envasadas en tubos de ensayo pero que con frecuencia lo fue en botellas de medicina que había tomado Maciunas (recuérdese su enfermedad y su afición al consumo de los fármacos, que fue también punto de partida para alguna de las obras de S. Kubota). Carla Liss diseñó para el caso unas etiquetas variadas que retomaban imágenes de diversa extracción estilística que pasaban de la referencia egipcia a las de un tratamiento barroco en las que se insistía en el aspecto ritual e iniciación evocado por el título.

Para otras obras Fluxus de Carla Liss el diseño de etiquetas fue realizado por el propio Maciunas, como en el caso de Kat flux kit (1973), trabajo que nunca se llegó a producir, pero cuyo nombre fue incluido en el diagrama del desarrollo histórico de Fluxus. La etiqueta realizada por Maciunas de especial tensión expresiva parece distorsionar el sentido afectivo que Carla hubiera dado al trabajo debido a su amor por los gatos (Fluxus Codex, p. 315), que le llevó, por ejemplo, a organizar en el mismo año Intercat 73 un Festival Internacional Cat Film en Londres.

Ella siguió trabajando en Nueva York en sus Entornos-films (film environments) como Dovecote, en instalaciones como Secrets of three Mile Island y video performances. 


\section{Carolee Schneemann.}

También Carolee Schneemann colaboró durante un tiempo con el grupo Fluxus durante los primeros años 60. Su formación se había completado en varias universidades como la de Illinois, la de Columbia, la de Puebla (México) y también en la School of Painting and Sculpture de Nueva York, así como en New School for Social Research de Nueva York, un centro emblemático para quienes siguieron después por la vía de la performance y la experimentación artística. En el periodo 1956-1962 se vincula al Judson Dance Theater de Nueva York, y a partir de 1963 elabora performances. De ese mismo año es Chromolodeon o Meat Joy de 1964 época en la que se encuentra más cercana a Fluxus. Estas obras y algunas otras: Water Light/Water Needle de 1966 la autorizan ya como una de las grandes figuras del arte de acción, en este caso paulatinamente más comprometida con la investigación sobre el cuerpo y su implicación social, evolucionando hacia un arte de género que, de una manera más explícita en la década de 1970, cuestiona las ideas preconcebidas sobre los roles y las sexualidades tradicionalmente descritas.

Desde el punto de vista formal se debe señalar su interés por los trabajos intermedia, utilizando recursos derivados de soportes y técnicas diferentes. Le ha interesado igualmente el mundo de las instalaciones, así como el cine (Fuses) y el vídeo.

Sus trabajos de pintura se mezclan en expresión abstracta realizada en la estela pintura de acción con anticipaciones del body-art y el interés por la síntesis de distintos medios expresivos, como ya hemos mencionado más arriba. En Eye Body (1963) como en Four Fur Cutting se advierten estas características. El cuerpo de Schneeman es soporte e instrumento, pero también conocimiento y creatividad asociada que no precisa de las manos para expresarse, es todo él expresión del saber creativo. Eye Body fue presentado en el Kinetic Theater como un cuerpo entorno (instalación) collage para cámara.

En Meat Joy una de sus obras de los años 60 más conocida (Celebración de la Carne), Schneemann presentó una serie de efectos sonoros visuales para materializar entre otras cosas una revisión metafórica de las relaciones del cuerpo del artista con el cuerpo social, pero también para profundizar en un estudio de intersensorialidad. Se considera la obra como una acción collage en el que la pintura es sustituida en parte por sangre de reses muertas que es impreg- 
nada en el soporte gracias al movimiento de los cuerpos tanto de hombres como de mujeres que se iban incorporando gradualmente y cada vez en mayor número al happening. En la concepción de la obra, la artista no se planteó la determinación del material concreto que debía utilizarse, sino que prefirió atenerse al material trouvé igual que en el caso de quienes intervinieran. Consideraba que el azar es igualmente creador y por tanto que aquello que encontrase sería lo que la obra necesitase. A la sangre se le añadió la presencia de carne cruda también de peces y de pollos. La obra incorporaba además diapositivas de Arman, trabajos de J. Weber y H. Migdoll y collages sonoros de James Tenney, elaboraciones visuales y sonoras de J. Lifton y la propia Carolee Schneemann. Se presentó en la Hudson Memorial Church de Nueva York y también en París. Con intenciones distintas la utilización de la sangre y la interacción cuerpo humano - cuerpo de animales muertos o fragmentos de ellos sitúa a Scheemann en las experimentaciones que llevaron a cabo por aquellas fechas otros grupos del arte de acción, por ejemplo Nitsch y el grupo de acción vienés.

Las relaciones con los artistas del Fluxus fueron buenas, de hecho ella colaboró en obras de algunos de los miembros del entorno. Ya hemos mencionado su conexión con Yoko Ono y su participación en el Film no 4 (Bottoms) de esta, e igualmente conectó bien con Takako Saito, Alison Knowles y muchos otros, sin embargo el problema surgió con Maciunas que no aceptó bien la libertad con la que Carolee mostraba su cuerpo y su sexualidad en sus trabajos. Ella aludirá directamente a este hecho en el texto que escribió titulado Fluxus (Ubi fluxus Ibi Motus, p. 89). En él llega a afirmar que Fluxus es una buena barca para navegar por el mundo del arte, pero no para quienes no lleven ropa interior o enseñen su anatomía sexual. En este sentido se refiere a la carta que "georges" (sic. ibidem) escribió sobre los delitos que ella cometía en sus obras. Es lógico pensar que ese fue el detonante de su alejamiento de Fluxus.

Ya desvinculada del grupo ha realizado obras de referencia como por ejemplo Interior Scroll en sus diferentes versiones (del 75, 77 y las variaciones de esta) en las que insiste de manera aún más libre sobre el cuerpo femenino como fuente de conocimiento y en la reivindicación de la libertad sexual.

A su actividad artística se debe añadir la mención a su dedicación a la reflexión teórica y la escritura. Ha publicado diversos textos entre los que destaca 
More Than Meat Joy que recopila la totalidad de sus performances y selecciona algunos de sus textos más destacados (Schneemann, 1996).

Menos peso tendrán las obras de Jane Knizak (Fluxus Codex, p. 294) y más laterales respecto al grupo son los trabajos de Marian Zazeela -con su original desarrollo de la escultura-luz-, Sara Segull y otras, que colaboraron únicamente de forma puntual. Todas ellas contribuyeron a edificar un arte más libre y con su esfuerzo, apoyo y entusiasmo se ganaron un puesto en la memoria colectiva. Contribuir a mantener vivo ese recuerdo ha sido el objetivo de este trabajo.

\section{Bibliografía}

COZEN, I. (1997): Art Games. Die Schachtein der Fluxuskünstler. Oktagon Verlag. Staatsgalerie Stuttgart.

CROW, Th. (2001): El esplendor de los sesenta. Madrid. Akal.

Fluxus. Today and Yesterday. Número monográfico de la Revista Art and Desing Magazine. № 28. Academy Editions. London, 1993.

Fluxus y Dino Di Maggio en el Museo Vostell de Malpartida, (1998): Consorcio Museo Vostell de Extremadura, Junta de Extremadura. Cáceres-Badajoz.

GOLDBERG, Roselee (1998): Performance. Live Art since the 60s. London-Singapur.

GoldBerg, Roselee (1996): Performance Art. Destino, Thames and Hudson.

Colección El mundo del Arte. Barcelona.

Happening and Fluxus. Materialien (1970): Belnischer kunstverein.

Happening, Fluxux y otros comportamientos artísticos de la segunda mitad del siglo XX. Actas del Simposio de Cáceres. Universidad de Extremadura 2001.

HASKELL, B (1991): Yoko Ono, Arias and Object. Peregrine Smith Book.

Hendrick, J. (1988): Fluxus Codex. The Gilbert and Lila Silverman Fluxus Collection, Detroit, Michigan. In association wicth Harry N. Abrams, Inc., Publishers, N. York.

JACOB, Mary Jane (ed.) (1991): Shigeko Kubota. Video Sculpture. New York, American Museum of Moving Image.

KeLLEIN, Th. (1995): Fluxus. Thames and Hudson. London-New York. 
L’Esprit de Fluxus (1994) Barcelona. Fundación Tapies.

AuBERT, M. - GUESS, J. (1998): Flux Film. París. Revoir Video editions.

MiLlet, K. (1995): Política sexual (1969). Prólogo a la edición española de Amparo Moreno. Madrid, Cátedra.

MiLleT, K. (1990): En pleno vuelo (1974). Barcelona. Ed. Hacer y Madrid Ed. Vindicación Feminista.

MunROE, A., HENDRICKS, J., y otros (2000): Yes Yoko Ono. New York Japan Society. H.N. Abrams.

NeAD, L. (1998): El desnudo femenino. Arte, obscenidad y sexualidad. Madrid. Tecnos.

Out of actions. Between Performance and the Object 1949-1979. Thames and Hudson. 1998. Hay edición en catalán.

RUHE, Harry (1979): Fluxus. The most radical and experimental art movement of the sixties. Amsterdam.

SCHneEman, Carolee. More than Meat Joy: Complete Performance works and selected writings. Ed. de Bruce MacPherson. New York. New Paltz. 1979. (2o ed. 1996).

SiCHEL, Berta y FRANK, Peter (Eds.) (2002): Fluxus. Fluxfilm. Centro de Arte Reina Sofía, Madrid.

TANNER, Marcia (1994): "Mother Laughed: The Bad Girls Avant-Garde" en Bad Girls. Catalogue. New York. The New Museum of Contemporary Art, pp. 59-65.

WENNER, J. (1975): Lennon Recuerda. Entrevistas publicadas en la revista Rolling Stone. Madrid, Akal.

YOKO ONO (1989): “Cambio y supervivencia. La historia de todos nosotros". Revista Arena. № 2.

ZAYA, O (1989): “Zaj y Fluxus”. Revista Arena. № 2. 